Terbit online pada laman web jurnal: http://journal.isas.or.id/index.php/JASENS

\begin{tabular}{c}
\hline JOURNAL OF APPLIED SMART ELECTRICAL \\
NETWORK AND SYSTEMS (JASENS) \\
\hline ISAS
\end{tabular}

\title{
Implementasi Lampu Peringatan Pada Perlintasan Tanpa Palang Pintu Kereta Api Berbasis Wireless Sensor Network
}

\author{
Aad Hariyadi ${ }^{1}$, Moh. Syakur Romadhoni², M. Abdullah Anshori ${ }^{3}$, Amalia Eka Rakhmania ${ }^{4}$ \\ 1,2,3,4 Jurusan Teknik Elektro, Politeknik Negeri Malang \\ ${ }^{1}$ aad.hariyadi@polinema.ac.id, ${ }^{2}$ romadhonidelapantujuh@gmail.com, ${ }^{3}$ moh.abdullah@polinema.ac.id, \\ ${ }^{4}$ amaliaeka.rakhmania@polinema.ac.id*
}

\begin{abstract}
This research aims to make a warning light with a microcontroller base as a control system. To reduce the use of manual systems in general that are in use today. The advantage of this warning light control system is that it functions to reduce the number of accidents that occur and can be used for railroad crossings where there are still no latches that have not been installed on the railroad crossing (wild road). The display of the work system that is made will be monitored using a web monitoring display that supports and is easy to understand. Even though it has some delay in the process, the planned system has run well based on the average delay value. The experimental results show the average delay measured in the system is 0.31 seconds before sending from the node and 0.49 seconds when there is a change in conditions, while when there is data transmission from the node. The measured packet loss on the system is $0 \%$ before transmission and fans and $8.88 \%$ when data is transmitted from the node.
\end{abstract}

Keywords: Reverse Parking Sensor, Local Server, LoRa, Microcontroller, Warning Light.

\begin{abstract}
Abstrak
Penelitian ini bertujuan untuk membuat lampu peringatan dengan basis mikrokontroler sebagai sistem kendalinya. Untuk mengurangi penggunaan sistem manual pada umumnya yang di gunakan saat ini. Kelebihan dari sistem kendali warning light ini adalah berfungsi untuk mengurangi angka kecelakaan yang terjadi dan dapat digunakan untuk perlintasan kereta api dimana masih belum ada gerendel yang belum terpasang pada perlintasan kereta api (perlintasan liar). Tampilan sistem kerja yang dibuat akan dimonitor menggunakan tampilan web monitoring yang mendukung dan mudah dipahami. Meskipun terdapat beberapa keterlambatan dalam prosesnya, namun sistem yang direncanakan telah berjalan dengan baik berdasarkan nilai delay rata-rata. Hasil eksperimen menunjukkan rata-rata delay yang terukur pada sistem adalah 0,31 detik sebelum pengiriman dari node dan 0,49 detik saat terjadi perubahan kondisi, sedangkan saat ada pengiriman data dari node. Packet loss yang terukur pada sistem adalah $0 \%$ sebelum transmisi dan kipas dan $8,88 \%$ saat data ditransmisikan dari node.
\end{abstract}

Kata kunci: Sensor Parkir Mundur, LocalServer, LoRa, Mikrokontroller, Lampu Peringatan.

Diterima Redaksi : 24-05-2021 | Selesai Revisi : 22-06-2021 | Diterbitkan Online : 30-06-2021

\section{Pendahuluan}

Perlintasan kereta api adalah perpotongan sebidang antara jalur kereta api dengan jalan. Isu yang menonjol Perkembangan teknologi dan transportasi saat ini pada perlintasan sebidang adalah tingginya angka menggunakan sistem kontrol sebagai salah satu kecelakaan lalu-lintas antara kendaraan dengan kereta penunjang yang kegunaannya sangat besar terutama api, terutama pada perlintasan yang tidak memiliki pada transportasi kereta api. Tanpa pemanfaatan sistem palang pintu.

Kecelakaan lalu lintas pada perlintasan rel kereta api kerap terjadi akhir - akhir ini di indonesia. Penyebab terjadinya kecelakaan karena tidak adanya palang pintu perlintasan, kegagalan pintu menutup saat dibutuhkan atau kegagalan operator untuk memerintahkan penutupan pintu perlintasan. Dalam rangka mengurangi kecelakaan lalu lintas pada perlintasan kereta api perlu kiranya setiap lintasan diberikan palang pintu perlintasan [1].

kontrol maka kemajuan teknologi akan sulit berlangsung. Salah satu teknologi yang diterapkan yaitu sistem pengontrolan secara otomatis dalam palang pintu kereta api. Dalam penerapan sistem kontrol otomatis yang dapat membaca objek pada perlintasan kereta api pada saat melewati palang pintu perlintasan dengan berbasis mikrokontroler [2].

Potensi terjadinya kecelakaan yang disebabkan oleh perkeretaapian yang operasinya dapat dikontrol 
merupakan "sebagian permasalahan", sedangkan dimana LoRa RF1276 sebagai modul transmisi antar "sebagian permasalahan" lainnya yaitu kendaraan jalan Arduino Uno.

raya dapat dikatakan tidak sepenuhnya mampu dikontrol oleh satu entitas. Sistem yang pernah dibuat atau direncanakan oleh pemerintah saat ini seperti PDPS masih tergolong mahal untuk biaya pembuatannya. Penelitian ini bertujuan untuk membangun suatu sistem peringatan kereta api yang relatif aman dan murah dengan menggunakan sensor ultrasonik dan mikrokontroler sebagai pengendali sistemnya. Cara kerja sistem ini sangat sederhana. Lampu merah akan menyala apabila ada kereta yang melewati sensor pertama yang terletak sebelum perlintasan, diikuti dengan lampu panah kanan/kiri untuk bertujuan memberi tahu arah kereta yang akan melintas. Lampu merah akan padam dan lampu hijau menyala setelah kereta melewati sensor kedua yang letaknya berada setelah perlintasan. Dan hasil dari penelitian ini dapat berjalan sesuai dengan tujuan. Lampu merah menyala pada saat ada benda yang melintasi sensor, dan lampu merah akan menjadi hijau pada saat benda tersebut melintasi sensor setelahnya.

Untuk membuat sebuah lampu peringatan dengan basis mikrokontoler sebagai sistem kontrol. Dengan tujuan mengurangi penggunaan sistem manual pada umumnya yang di pakai saat ini. Kelebihan sistem kontrol lampu peringatan ini berfungsi mengurangi angka kecelakaan yang terjadi dan bisa di manfaatkan untuk perlintasan kereta yang masih belum ada palang pintu yang belum terpasang di jalan raya rel perlintasan kereta api (jalan liar).

\section{Metode Penelitian}

\subsection{Wireless Sensor Network}

Wireless Sensor Network atau jaringan sensor nirkabel adalah kumpulan sejumlah node yang diatur dalam sebuah jaringan kerjasama. Masing-masing node dalam jaringan sensor nirkabel biasanya dilengkapi dengan radio transceiver atau alat Komunikasi wireless lainnya, mikrokontroler, dan sumber energi seperti baterai. Banyak aplikasi yang bisa dilakukan menggunakan jaringan sensor nirkabel, misalnya pengumpulan data kondisi lingkungan [3-6]. Jaringan sensor ini harus pandai membaca kondisi objek yang dibaca kondisinya(sensing). Selain itu juga node sensor harus memiliki kepekaan atau sensitivitas yang tinggi. Pada node sensor tidak hanya berkomunikasi dengan sesama sensor melainkan dengan basestation yang menggunakan jaringan radio nirkable. Pada base station dilakukan analisa, monitoring dan penyimpanan data hasil sensing[7].

\subsection{Rancangan Penelitian}

Untuk mengetahui lampu peringatan aktif atau non aktif, menggunakan sensor parkir mobil (mundur). Selanjutnya, data yang diinputkan oleh sensor mundur dikirim ke Arduino Uno 1. Lalu, untuk mengirimkan data ke Arduino Uno 2 dibutuhkan LoRa RF1276,

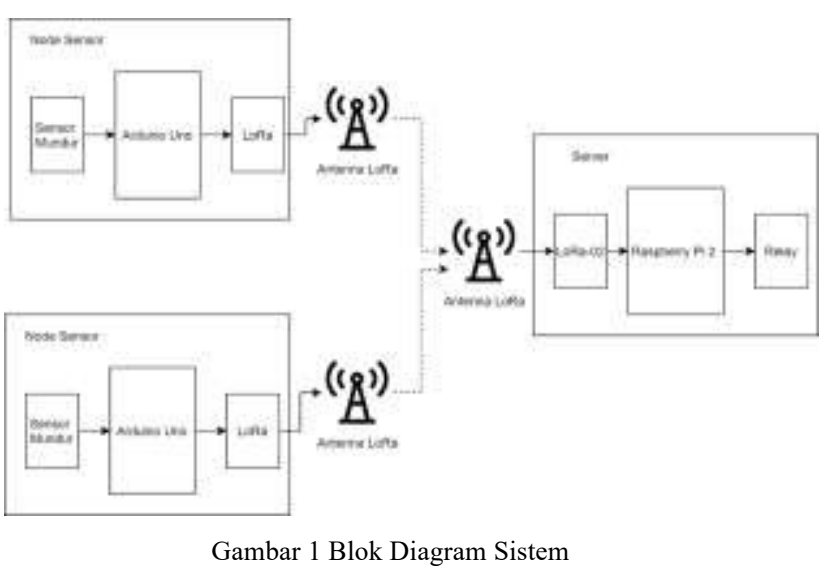

Apabila data Arduino Uno 1 diterima oleh Arduino 2, maka keluaran data tersebut berupa lampu led yang menjadi perantara peringatan bahwa kereta akan melintas dan seketika buzzer dan led petunjuk arah kereta lewat akan aktif [8]. Gambar 1 menjelaskan bahwa perangkat pendeteksian terdiri dari sensor mundur, arduino uno, arduino nano 1, arduino nano 2, modul LoRa Sx1278, buzzer, relay dan LED. Setiap bagian tersebut memiliki perannya masing-masing. Untuk node sensor terdiri atas beberapa komponen, diantaranya Lora sebagai antenna komunikasi antara node ke server. Mikroprosesor yang digunakan adalah Arduino Uno yang bertugas untuk mengendalikan kerja node. Pada node sensor menggunakan sensor mundur yang digunakan untuk mendeteksi kereta yang lewat. Node sensor diletakan 500 meter arah kanan dari perlintasan dan 500 meter arah kiri dari perlintasan.

Untuk server terdapat Raspberry Pi sebagai singleboard computer sebagai pusat kendali sistem. Data yang dikirim oleh node akan masuk ke Raspberry Pi akan dijadikan nilai acuan untuk menyalakan lampu berdasarkan relay yang diaktifkan oleh Raspberry Pi [9]. Data dari node masuk ke server diterima oleh antenna LoRa sebagai perangkat komunikasi wireless pada sistem WSN yang digunakan. Relay digunakan untuk mengaktifkan lampu indikator sesuai data yang diterima guna menandakan arah kereta datang.

\subsection{Perancangan Alat}

Perancangan alat dibuat skematik terlebih dahulu, dihububungkan sesuai dengan GPIO untuk fungsi setiap pin pada masing-masing komponen. Perancangan alat yang akan dibuat ditunjukan pada gambar 2 dan 3 .

\subsection{Tampilan Web dan History}

Hasil dari penelitian ini juga memiliki output pada raspberyy pi berupa tampilan website yang masih menggunakan fasilitas localhost, serta pada web juga akan ditampilkan history pendeteksian oleh sensor [10]. 


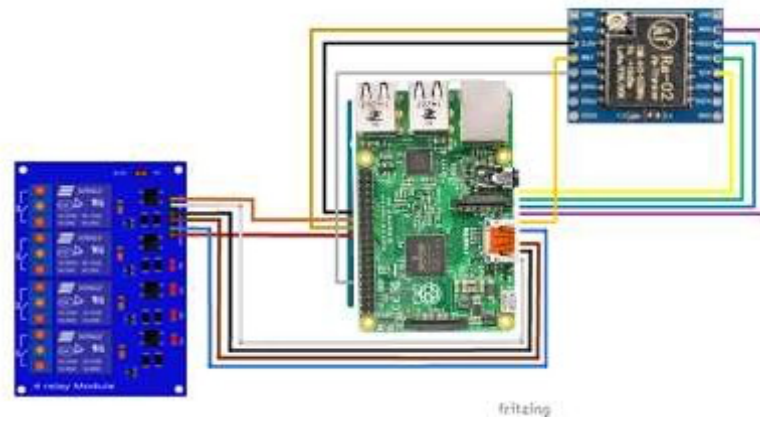

Gambar 2 Skematik Perancangan Node Server

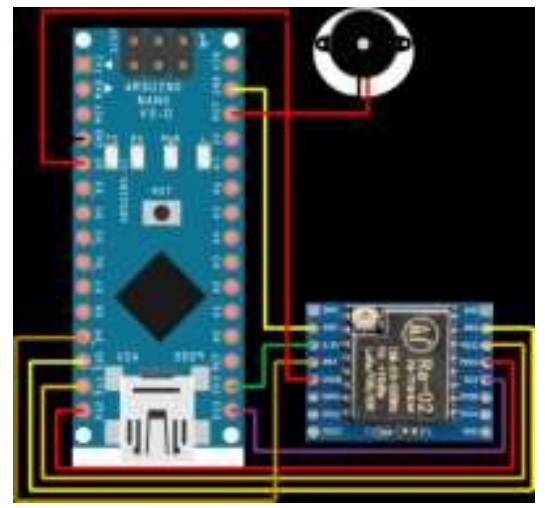

Gambar 3 Skematik Perancangan Node Sensor

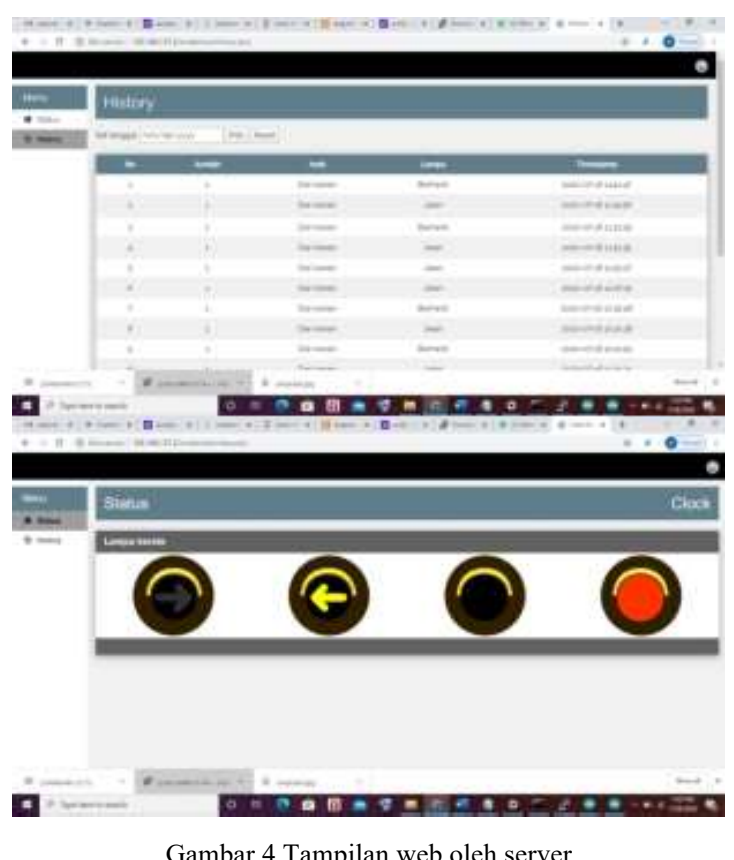

\section{Hasil dan Pembahasan}

\subsection{Pengujian Fungsional}

Pengujian fungsional dilakukan untuk melihat kesesuaian fungsi-fungsi dari tujuan awal sistem dibuat.Hasil pengujian fungsional dapat dilihat pada Tabel I.
Tabel 1. Hasil Pengujian Fungsional Sistem

\begin{tabular}{ccc}
\hline No. & Fungsi & $\begin{array}{c}\text { Hasil } \\
\text { Pengujian }\end{array}$ \\
\hline 1 & Node Sensor dapat mengambil data sensor & Berhasil \\
2 & Node Sensor dapat mengirim data ke server & Berhasil \\
3 & Server mengolah data yang diterima & Berhasil \\
4 & Server menghidupkan lampu sesuai node yang & Berhasil \\
& mengirim & \\
5 & Data pada web berubah sesuai data diterima & Berhasil \\
\hline
\end{tabular}

\subsection{Pengujian dengan Kereta Api}

Berikutnya dilanjutkan dengan pengujian sistem yang dirancang dengan objek yang sesungguhnya yaitu mendeteksi lewatnya kereta api. Pengujian dilakukan selama 6 hari. Dan kereta yang diuji kereta BIMA dan LOKOMOTIV DINAS. Pengujian node dari kiri objek kereta apinya adalah LOKOMOTIV DINAS dan pengujian node ke 1 objek kereta apinya adalah kereta BIMA. Berikut tabel hasil pengujian yang dilakukan beserta gambarnya.

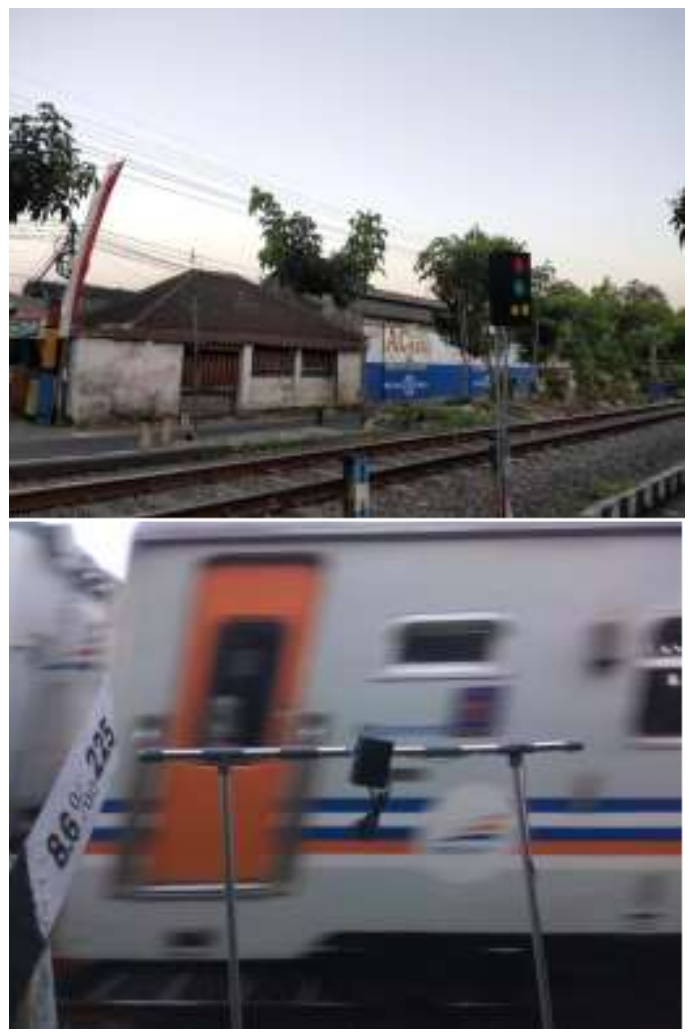

Gambar 5 Pengujian pada objek rel kereta api.

Berdasarkan pengujian yang dilakukan selama 7 hari dengan menyesaikan jadwal lintas kereta api BIMA setiap node dan server berhasil transmisi data dengan baik. Berdasarkan table II didapatkan hasil bahwa nilai rata-rata nilai delay paling besar didapatkan pada pengiriman dengan jarak paling jauh. Sehingga dapat 
dikatakan bahwa semakin jauh jarak node dengan objek maka delay yang didapatkan akan semakin besar.

Tabel 3 Pengujian Node Sensor

\begin{tabular}{|c|c|c|c|c|c|}
\hline No & $\begin{array}{c}\text { Hari dan } \\
\text { tanggal }\end{array}$ & $\begin{array}{l}\text { Waktu } \\
\text { (WIB) }\end{array}$ & $\begin{array}{c}\text { Jarak sensor } \\
\text { dari kereta } \\
(\mathrm{cm})\end{array}$ & $\begin{array}{c}\text { Status } \\
\text { deteksi }\end{array}$ & $\begin{array}{l}\text { Waktu } \\
\text { Deteksi } \\
\text { (detik) }\end{array}$ \\
\hline 1 & Kamis, 6 & 08.38 & 150 & Berhasil & 1,7 \\
\hline 2 & Agustus & 13.02 & 200 & Berhasil & 2 \\
\hline 3 & 2020 & 16.25 & 250 & Berhasil & 2,15 \\
\hline 4 & Selasa, & 08.40 & 150 & Berhasil & 1,85 \\
\hline 5 & 11 & 13.04 & 200 & Berhasil & 2,1 \\
\hline 6 & $\begin{array}{l}\text { Agustus } \\
2020\end{array}$ & 16.20 & 250 & Berhasil & 2,38 \\
\hline 7 & Rabu, 12 & 08.35 & 150 & Berhasil & 1,75 \\
\hline 8 & Agustus & 13.00 & 200 & Berhasil & 1,98 \\
\hline 9 & 2020 & 16.32 & 250 & Berhasil & 2,3 \\
\hline 10 & Kamis, & 08.41 & 150 & Berhasil & 2 \\
\hline 11 & 12 & 13.07 & 200 & Berhasil & 2,1 \\
\hline 12 & $\begin{array}{l}\text { Agustus } \\
2020\end{array}$ & 16.30 & 250 & Berhasil & 2,31 \\
\hline 13 & Senin, 16 & 08.45 & 150 & Berhasil & 1,85 \\
\hline 14 & Agustus & 12.58 & 200 & Berhasil & 2 \\
\hline 15 & 2020 & 16.31 & 250 & Berhasil & 2,18 \\
\hline 16 & Rabu, 18 & 08.36 & 150 & Berhasil & 1,9 \\
\hline 17 & Agustus & 13.00 & 200 & Berhasil & 2,1 \\
\hline 18 & 2020 & 16.25 & 250 & Berhasil & 2,45 \\
\hline 19 & Kamis, & 08.35 & 150 & Berhasil & 1,73 \\
\hline 20 & 19 & 13.08 & 200 & Berhasil & 1,95 \\
\hline 21 & $\begin{array}{c}\text { Agustus } \\
2020\end{array}$ & 16.30 & 250 & Berhasil & 2,25 \\
\hline
\end{tabular}

3.3 Pengujian Sistem Komunikasi LoRa dari Node ke Server Bandwidth Video

Pengujian performansi LoRa Antares dilakukan untuk mengetahui kualitas jalur komunikasi data yang optimal. Pengujian data dimulai dari jarak terderkat sampai terjauh. Refrensi untuk menentukan Panjang awal adalah satu kereta penumpang yang biasanya menarik 7 gerbong penumpang dan satu Panjang gerbong adalah 2 meter. Sehingga start pengujiannya mulai jarak 14 meter antara node dan server.

Tabel 3 Pengujian RSSI dari node 1 ke server

\begin{tabular}{cccc}
\hline Jarak node ke & \multicolumn{3}{c}{ RSSI $(\mathrm{dBm})$} \\
\cline { 2 - 4 } server (meter) & Maksimum & Minimum & Rata-rata \\
\hline 14 & -108 & -111 & $-109,5$ \\
20 & -111 & -112 & $-111,5$ \\
26 & -114 & -116 & -115 \\
32 & -118 & -120 & -119 \\
48 & -122 & -124 & -123 \\
54 & -125 & -127 & -126 \\
\hline
\end{tabular}

Dari tabel 4 bisa dilihat bahwa semakin jauh jarak node 1 dari sever maka nilai RSSI yang didapat juga semakin kecil. Nilai rata rata RSSI terbesar adalah untuk jarak 14 meter dengan nilai $-27 \mathrm{dBm}$, sedangkan untuk nilai rata rata RSSI terendah adalah untuk jarak 54 meter dengan nilai rata rata RSSI $-55 \mathrm{dBm}$. Dari tabel 7 bisa dilihat bahwa semakin jauh jarak node 1 dari sever maka nilai RSSI yang didapat juga semakin kecil. Nilai rata rata RSSI terbesar adalah untuk jarak 14 meter dengan nilai $-32 \mathrm{dBm}$, sedangkan untuk nilai rata rata RSSI terendah adalah untuk jarak 54 meter dengan nilai rata rata RSSI $-55.5 \mathrm{dBm}$.
Tabel 4 Pengujian RSSI dari node 2 ke server

\begin{tabular}{cccc}
\hline Jarak node ke & \multicolumn{3}{c}{ RSSI (dBm) } \\
\cline { 2 - 4 } server (meter) & Maksimum & Minimum & Rata-rata \\
\hline 14 & -109 & -111 & -110 \\
20 & -112 & -115 & $-113,5$ \\
26 & -117 & -118 & $-117,5$ \\
32 & -120 & -122 & -121 \\
48 & -123 & -125 & -124 \\
54 & -126 & -129 & $-127,5$ \\
\hline
\end{tabular}

\subsection{Pengujian Delay dan Packet Loss Data Pada Sistem}

Nilai pengiriman paket dari server ke client berjalan stabil dan tidak ada packet loss ketika tidak ada perubahan status, sementara ketika ada perubahan status nilai packet loss ada kenaikan sebesar 8,88\% merupakan kategori kondisi pengiriman data yang sedang sesuai dengan tabel yang ada pada bab 2. Delay rata rata yang terukur pada saat sebelum ada pengiriman dari node adalah 0,318 detik sedangkan ketika ada pengiriman data dari node delay rata rata yang terukur menjadi 0,491 detik. Pada tabel diatas perubahan kondisi ketika ada pengiriman dari node juga mempengaruhi delay pada komunikasi antara server dan client menjadi lebih besar.

\section{Kesimpulan}

Pengujian sistem yang dibuat memiliki tingkat keberhasilan 100 persen untuk pendeteksian objek untuk node kanan dan node kiri. Sedangkan pengiriman data yang digunakan juga berhasil 100 persen untuk node kanan dan node kiri. Untuk delay pembacaan sensor semakin jauh dari objek yang dideteksi maka akan semakin besar. Dimana pada node 1 delay terendah dengan jarak $100 \mathrm{~cm}$ dari objek dengan nilai 1.8 detik dan delay tertinggi bernilai 2.07 detik dengan jarak $225 \mathrm{~cm}$. Untuk node 2 delay terendah dengan jarak 100 $\mathrm{cm}$ dari objek dengan nilai 1.83 detik dan delay tertinggi bernilai 2.05 detik dengan jarak $225 \mathrm{~cm}$. Untuk RSSI nya semakin jauh jarak lora dari server maka RSSInya semakin jelek. Untuk node 1 nilai RSSI tertingginya $109.5 \mathrm{dBm}$ untuk jarak 14 meter dan terendah $-126 \mathrm{dBm}$ sedangkan untuk node 2 nilai RSSI tertingginya -110 $\mathrm{dBm}$ untuk jarak 14 meter dan terendah $-127.5 \mathrm{dBm}$.

Sistem yang dibangun memiliki nilai QOS yang baik dan sedang pada saat pengujian delay dan packet loss. Delay rata rata yang terukur pada sistem adalah 0,31 detik pada saat sebelum ada pengiriman dari node dan 0,49 detik ketika ada perubahan kondisi sedangkan ketika ada pengiriman data dari node dimana delay dikategorikan pada tingkat sangat baik. Packet loss yang terukur pada sistem adalah $0 \%$ pada saat sebelum ada pengiriman dan kipas angin dan $8,88 \%$ ketika ada pengiriman data dari node packet loss yang terukur dikategorikan pada tingkat sedang. 


\section{Daftar Rujukan}

[1] A. Syahputri, "Rancang Bangun Palang Pintu Otomatis Berbasis Mikrokontroler Menggunakan Kartu RFID dan Photodioda," 2018.

[2] M. Kusriyanto and N. Wismoyo, "Sistem palang pintu perlintasan kereta api otomatis dengan komunikasi," Teknoin, vol. 23, no. 1, pp. 73-80, 2017.

[3] M. Alhasan M, "Implementasi Wireless Sensor Network sebagai Pendeteksi Kebakaran Berbasis Lora," no. 2019-08-19, pp. 1-82, 2019.

[4] W. Puspitasari and H. Y. Perdana R, "Real-Time Monitoring and Automated Control of Greenhouse Using Wireless Sensor Network: Design and Implementation," 2018 International Seminar on Research of Information Technology and Intelligent Systems (ISRITI), 2018, pp. 362-366, doi: 10.1109/ISRITI.2018.8864377.

[5] H. Darmono, R. H. Y. Perdana, and W. Puspitasari, "Observation of greenhouse condition based on wireless sensor networks," IOP Conf. Ser. Mater. Sci. Eng., vol. 732, no. 1, 2020.

[6] R. H. Y. Perdana, H. Hudiono and A. F. N. Luqmani, "Water Leak Detection and Shut-Off System on Water Distribution Pipe Network Using Wireless Sensor Network," 2019 International
Conference on Advanced Mechatronics, Intelligent Manufacture and Industrial Automation (ICAMIMIA), 2019, pp. 297-301, doi: 10.1109/ICAMIMIA47173.2019.9223386.

[7] Muhamad Ridwan, "Implementasi Kontrol Lampu Rumah Menggunakan Arduino Uno Berbasis Android,” 2018.

[8] Raka Satria Pradana H.D., "Rancang Bangun Pengendali Utama Pada Sistem Kontrol Dan Monitoring Lampu Penerangan Jalan Umum Tenaga Surya Menggunakan Wireless Sensor Network Dengan Human Machine Interface Terpusat," Inst. Teknol. Sepuluh Nop. Surabaya, vol. 01, pp. 1-17, 2017.

[9] Ifa Afidah Rosuliya, "Implementasi Routing Protokol Wireless Sensor Network Pada Mikrokontroler Implementation Routing Protocol Wireless Sensor Network of Microcontroller Based," 2015

10]H. Hudiono, M. Taufik, R. H. Y. Perdana, and W. R. Rohmah, "Design and implementation of centralized reading system on analog postpaid water meter," in IOP Conference Series: Materials Science and Engineering, 2020, vol. 732, no. 1. 